\title{
Article \\ Improving Breakdown Voltage and Threshold Voltage Stability by Clamping Channel Potential for Short-Channel Power p-GaN HEMTs
}

\author{
Hongyue Wang ${ }^{1, *}$, Yijun Shi ${ }^{1}$, Yajie Xin ${ }^{2, *}$, Chang Liu ${ }^{1} \mathbb{D}$, Guoguang Lu $^{1}$ and Yun Huang ${ }^{1}$ \\ 1 Science and Technology on Reliability Physics and Application of Electronic Component Laboratory, China \\ Electronic Product Reliability and Environmental Testing Research Institute, Guangzhou 510610, China; \\ syijun0119@163.com (Y.S.); xd_liuchang@163.com (C.L.); luguoguang@ceprei.com (G.L.); \\ hyun@ceprei.com (Y.H.) \\ 2 State Key Laboratory of Electronic Thin Films and Integrated Devices, University of Electronic Science and \\ Technology of China (UESTC), Chengdu 610054, China \\ * Correspondence: wanghongyue@pku.edu.cn (H.W.); 201811022423@std.uestc.edu.cn (Y.X.)
}

check for updates

Citation: Wang, H.; Shi, Y.; Xin, Y.; Liu, C.; Lu, G.; Huang, Y. Improving Breakdown Voltage and Threshold Voltage Stability by Clamping Channel Potential for Short-Channel Power p-GaN HEMTs. Micromachines 2022, 13, 176. https://doi.org/ $10.3390 / \mathrm{mi13020176}$

Academic Editors: Benoit Bakeroot and Matteo Meneghini

Received: 26 December 2021

Accepted: 14 January 2022

Published: 25 January 2022

Publisher's Note: MDPI stays neutral with regard to jurisdictional claims in published maps and institutional affiliations.

Copyright: () 2022 by the authors. Licensee MDPI, Basel, Switzerland. This article is an open access article distributed under the terms and conditions of the Creative Commons Attribution (CC BY) license (https:// creativecommons.org/licenses/by/ $4.0 /)$.

\begin{abstract}
This paper proposes a novel p-GaN HEMT (P-HEMT) by clamping channel potential to improve breakdown voltage $(\mathrm{BV})$ and threshold voltage $\left(V_{\mathrm{TH}}\right)$ stability. The clamping channel potential for P-HEMT is achieved by a partially-recessed p-GaN layer (PR p-GaN layer). At high drain bias, the two-dimensional electron gas (2DEG) channel under the PR p-GaN layer is depleted to withstand the drain bias. Therefore, the channel potential at the drain-side of the $\mathrm{p}-\mathrm{GaN}$ layer is clamped to improve BV and $V_{\mathrm{TH}}$ stability. Compared with the conventional p-GaN HEMT (C-HEMT), simulation results show that the BV is improved by $120 \%$, and the $V_{\mathrm{TH}}$ stability induced by high drain bias is increased by $490 \%$ for the same on-resistance. In addition, the influence of the PR p-GaN layers' length, thickness, doping density on BV and $V_{\mathrm{TH}}$ stability is analyzed. The proposed device can be a good reference to improve breakdown voltage and threshold voltage stability for short-channel power p-GaN HEMTs.
\end{abstract}

Keywords: breakdown voltage; partially recessed; p-GaN HEMT; short-channel

\section{Introduction}

GaN-based devices are promising for next-generation high-efficiency, high-frequency, high-temperature, and high-power applications due to their superior material properties [1-8]. According to the application requirements, it is necessary to improve the electric performance of GaN devices [9].

For power applications, low on-resistance $R_{\text {on }}$ and high breakdown voltage (BV) for GaN HEMTs are very desirable [7]. In order to realize low on-resistance, a short length scheme is always chosen as channel resistance under the gate is the main part of the total resistance for AlGaN/GaN HEMTs [10]. However, the short channel GaN HEMTs often suffer from the adverse drain-induced barrier lowering (DIBL) effect [11], namely, degradation of forward-blocking characteristics and negative threshold voltage $\left(V_{\mathrm{TH}}\right)$ shift at high drain bias [12,13]. In order to suppress the DIBL effect-induced BV degradation, Pinchbeck et al. proposed a GaN HEMT with extended gate length to achieve reduced short channel effect and improved BV [14]. In addition, Lu et al. proposed a dual gate AlGaN HEMT to achieve high BV, low on-resistance, and high threshold voltage characteristics [15]. However, those methods are not suitable for short-channel p-GaN HEMTs to suppress the BV degradation and $V_{\mathrm{TH}}$ instability, which owns a p-GaN layer to achieve enhancementmode function.

In this work, we proposed a novel p-GaN HEMT to improve the BV and $V_{\mathrm{TH}}$ stability, which features a partially-recessed p-GaN layer. At high drain bias, the two-dimensional 
electron gas (2DEG) channel under the partially-recessed p-GaN layer can withstand the high drain voltage to achieve higher $\mathrm{BV}$ and more stable $V_{\mathrm{TH}}$ for the short-channel p-GaN HEMTs. The paper is organized as follows: the device structure and operation mechanism of the proposed p-GaN HEMT are presented in Section 2; the simulation results and discussions are shown in Section 3; the conclusions are drawn in Section 4.

\section{Device Structure and Mechanism}

The schematic structure of the proposed p-GaN HEMT (P-HEMT) is shown in Figure $1 \mathrm{~b}$. Compared with conventional p-GaN HEMT (C-HEMT), the P-HEMT features a partially recessed layer (PR p-GaN layer). To illustrate the mechanism of improving $\mathrm{BV}$ and $V_{\mathrm{TH}}$ stability for the P-HEMT, we employ one equivalent model with two series HEMTs, which are defined as high threshold voltage HEMT1 and low threshold voltage HEMT2, as shown in Figure 2a. As the threshold voltage of HEMT1 $\left(V_{\mathrm{TH} 1}\right)$ is larger than the threshold voltage of HEMT2 $\left(V_{\mathrm{TH} 2}\right)$, HEMT2 has been turned on when the gate to source voltage $\left(V_{\mathrm{GS}}\right)$ is larger than $V_{\mathrm{TH} 1}$. Therefore, the threshold voltage $V_{\mathrm{TH}}$ of P-HEMT is mainly determined by $V_{\mathrm{TH} 1}$, namely, $V_{\mathrm{TH}} \approx V_{\mathrm{TH} 1}$. The potential is defined as $V_{\mathrm{C}}$ at the connection node, which is also shown in Figure 1 b. When $0<V_{\mathrm{C}}<V_{\mathrm{GS}}-V_{\mathrm{TH} 2}$ (i.e., $V_{\mathrm{GS}}-V_{\mathrm{C}}>V_{\mathrm{TH} 2}$ ), HEMT2 is at on-state. Therefore, $V_{\mathrm{C}}$ increases with $V_{\mathrm{DS}}$ at low drain bias. When $V_{\mathrm{C}}>V_{\mathrm{GS}}-V_{\mathrm{TH} 2}$ (i.e., $V_{\mathrm{GS}}-V_{\mathrm{C}}<V_{\mathrm{TH} 2}$ ), HEMT2 is in an off-state and the 2DEG channel under the PR $\mathrm{p}-\mathrm{GaN}$ layer is depleted to withstand $V_{\mathrm{DS}}$ voltage. Therefore, $V_{\mathrm{C}}$ is clamped and does not increase with $V_{\mathrm{DS}}$ at high drain bias, as the blue dash line shown in Figure 2b. As a result, the barrier height for electrons injecting from source to drain will be hardly influenced by high drain bias, which makes $V_{\mathrm{TH}}$ more stable. In addition, the stable barrier height leads to decreased electrons flowing from source to drain compared with C-HEMT at high drain bias, which induces delayed occurrence of avalanche breakdown, namely, improves breakdown voltage.

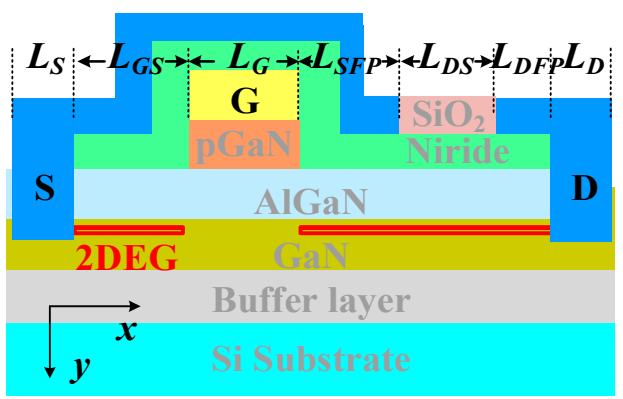

(a)

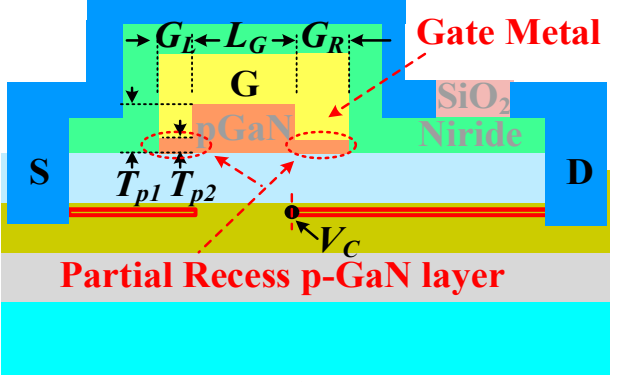

(b)

Figure 1. The schematic device structures of (a) conventional p-GaN HEMT (C-HEMT) and (b) proposed p-GaN HEMT (P-HEMT) with partially-recessed p-GaN layer (PR p-GaN layer).

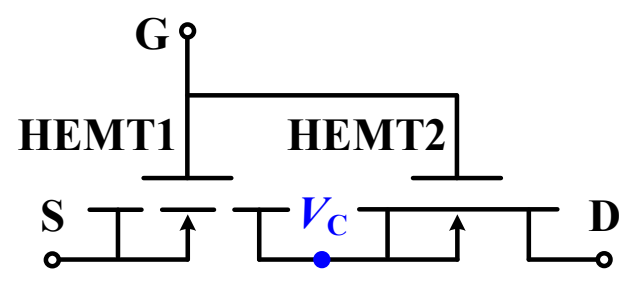

(a)

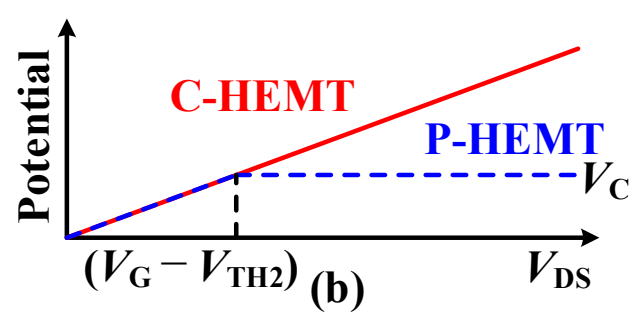

(b)

Figure 2. (a) The equivalent model of the P-HEMT with a high threshold voltage HEMT1 and a low threshold voltage HEMT2; (b) the potential $V_{\mathrm{C}}$ versus $V_{\mathrm{DS}}$.

\section{Results and Discussions}

In this section, the current-voltage and capacitance-voltage characteristics of P-HEMT are investigated by Sentaurus TCAD simulation software [16], and the design considerations are also discussed. In the simulation, the optimized device parameters are as 
listed in Table 1 unless otherwise specified, which is also based on our previous calibrated work [17]. In particular, the structure parameters of C-HEMT are designed according to the dissected cross-sectional scanning electron microscope (SEM) images. The $x-$ and $y$-coordinates and the epitaxial structures of the two devices are illustrated in Figure 1 [18]. For C-HEMT, an ionized acceptor concentration $N_{\mathrm{p}-\mathrm{GaN}}=3.5 \times 10^{17} \mathrm{~cm}^{-3}$ is induced in the p-GaN layer with the $t_{\mathrm{p}-\mathrm{GaN}}=50 \mathrm{~nm}$, which contributes to $V_{\mathrm{TH}}$ and on-state current calibrations for the C-HEMT. In addition, the deep acceptor traps and self-compensating donor traps [19] are also considered in the AlGaN buffer layer with an activation energy of $E_{\mathrm{V}}+0.9 \mathrm{eV}$ and $E_{\mathrm{C}}-0.11 \mathrm{eV}[20]$, and the trap density is $3 \times 10^{16} \mathrm{~cm}^{-3}$ and $1.3 \times 10^{15} \mathrm{~cm}^{-3}$ respectively [21]. Typically, the $G_{L}$ of the PR layer on the source side is only set to $0.1 \mu \mathrm{m}$ considering the deviation of the fabrication process, and it should be as small as possible to reduce the negative influence on input capacitance in practical application. The $G_{R}$ of the PR layer on the drain side is an adjustable parameter as it makes obvious significance on the improvement of BV and $V_{\mathrm{TH}}$ stability. In this paper, the gate length $L_{\mathrm{G}}$ of C-HEMT is the same as the length of the thicker $\mathrm{p}-\mathrm{GaN}$ layer of P-HEMT for achieving the same on-resistance, and the length of the partially-recessed p-GaN layer is not included in the nominal gate length $L_{\mathrm{G}}$. Table 1 shows the calibrated results of the $100 \mathrm{~V}$ enhancementmode p-GaN HEMT [22], and it can be seen that the results are in good agreement with the datasheet as shown in Figure 3. Typically, the BV characteristic considering the avalanche model [23] coincides well with the testing result.

Table 1. Device parameters specification.

\begin{tabular}{|c|c|c|}
\hline Symbols & Definitions & Typical Value \\
\hline$L_{\mathrm{S}}$ & Source length & $0.7 \mu \mathrm{m}$ \\
\hline$L_{\mathrm{G}}$ & Gate length & $0.35 \mu \mathrm{m}$ \\
\hline$L_{\mathrm{D}}$ & Source-to-gate length & $0.7 \mu \mathrm{m}$ \\
\hline$L_{\mathrm{GS}}$ & Source-to-gate length & $0.4 \mu \mathrm{m}$ \\
\hline$L_{\text {DS-C }}$ & C-HEMT Gate-to-drain length & $1.95 \mu \mathrm{m}$ \\
\hline$L_{\text {DS-PR }}$ & P-HEMT Gate-to-drain length & $1.95 \mu \mathrm{m}$ \\
\hline$L_{\mathrm{SFP}-\mathrm{C}}$ & C-HEMT Source-field-plate length & $0.8 \mu \mathrm{m}$ \\
\hline$L_{\mathrm{SF}-\mathrm{PR}}$ & P-HEMT Source-field-plate length & $\left(0.8-G_{\mathrm{r}}\right) \mu \mathrm{m}$ \\
\hline$L_{\text {DFP }}$ & Drain-field-plate length & $0.25 \mu \mathrm{m}$ \\
\hline$t_{\mathrm{SiN}}$ & Thickness of SiN & $80 \mathrm{~nm}$ \\
\hline$t_{\mathrm{SiO} 2}$ & Thickness of $\mathrm{SiO}_{2}$ & $270 \mathrm{~nm}$ \\
\hline$G_{\mathrm{L}}$ & The left PR p-GaN length & $0.1 \mu \mathrm{m}$ \\
\hline$G_{\mathrm{R}}$ & The right PR p-GaN length & $0.3 \mu \mathrm{m}$ \\
\hline$T_{\mathrm{p} 2}$ & Thickness of PR p-GaN & $30 \mathrm{~nm}$ \\
\hline$T_{\mathrm{p} 1}$ & Thickness of p-GaN & $50 \mathrm{~nm}$ \\
\hline$t_{\mathrm{ba}}$ & Thickness of barrier & $12.5 \mathrm{~nm}$ \\
\hline$t_{\mathrm{ch}}$ & Thickness of channel & $20 \mathrm{~nm}$ \\
\hline$t_{\mathrm{bu}}$ & Thickness of buffer & $2 \mu \mathrm{m}$ \\
\hline$t_{\mathrm{nu}}$ & Thickness of nucleation & $10 \mathrm{~nm}$ \\
\hline$t_{\text {sub }}$ & Thickness of substrate & $550 \mu \mathrm{m}$ \\
\hline$t_{\text {gate }}$ & Thickness of Schottky gate & $100 \mathrm{~nm}$ \\
\hline$\chi_{\text {ba }}$ & Al composition of barrier & $25 \%$ \\
\hline$\chi_{\text {bu }}$ & Al composition of buffer & $5 \%$ \\
\hline$W_{\mathrm{G}}$ & Work-function of the gate & $4.8 \mathrm{eV}$ \\
\hline$N_{\text {DT1 }}$ & Nitride/AlGaN trap density & $3 \times 10^{13} \mathrm{~cm}^{-2}\left(E_{\mathrm{C}}-0.4 \mathrm{eV}\right)[24]$ \\
\hline$N_{\text {DTC }}$ & Channel UID concentration & $1 \times 10^{15} \mathrm{~cm}^{-3}$ \\
\hline
\end{tabular}


Table 1. Cont.

\begin{tabular}{ccc}
\hline Symbols & Definitions & Typical Value \\
\hline$N_{\mathrm{AT} 1}$ & Buffer acceptor trap density & $3 \times 10^{16} \mathrm{~cm}^{-3}\left(E_{\mathrm{V}}+0.9 \mathrm{eV}\right)[17]$ \\
\hline$N_{\mathrm{DT} 2}$ & Buffer donor trap density & $1.3 \times 10^{15} \mathrm{~cm}^{-3}\left(E_{\mathrm{C}}-0.11 \mathrm{eV}\right)$ \\
\hline$N_{\mathrm{AT} 2}$ & Silicon/AlN acceptor trap density & $3 \times 10^{13} \mathrm{~cm}^{-2}\left(E_{\mathrm{C}}-1.7 \mathrm{eV}\right)$ \\
\hline$N_{\mathrm{p}-\mathrm{GaN}}$ & Activated Mg Doping & $3.5 \times 10^{17} \mathrm{~cm}^{-3}$ \\
\hline
\end{tabular}
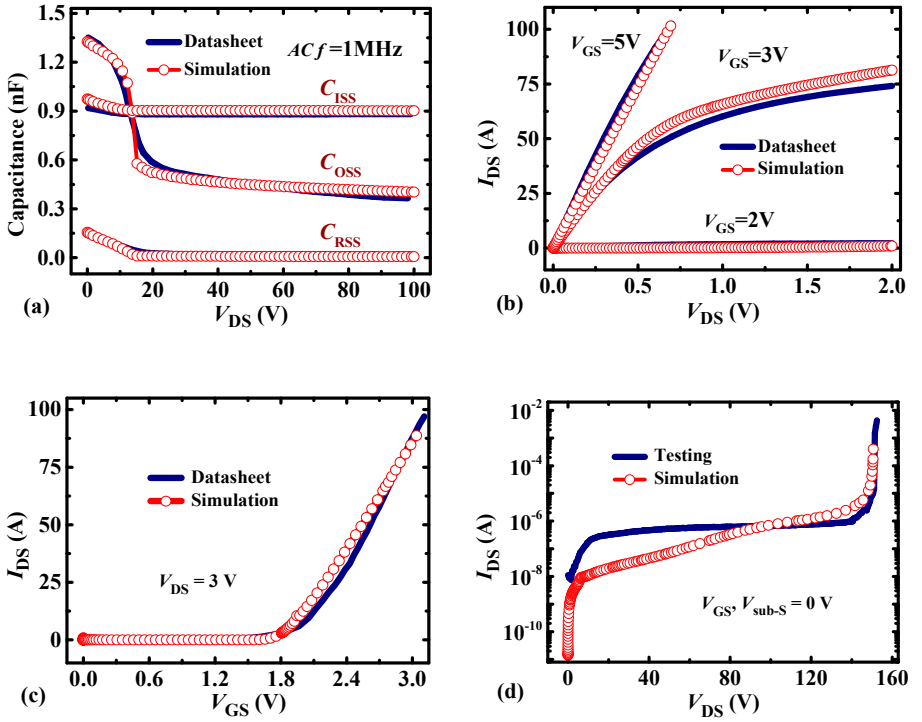

Figure 3. (a) Capacitance-Voltage characteristic; (b) output characteristic; (c) transfer characteristic; (d) forward-blocking characteristic. The forward-blocking characteristic is based on the testing data as there is no breakdown voltage result in the datasheet.

\subsection{Static and Transient Characteristics}

Figure 4 shows the forward-blocking and output characteristics of the P-HEMT. As shown in Figure $4 \mathrm{a}$, it can be seen that the BV $\left(I_{D_{\text {DS }} \text { off }}=100 \mu \mathrm{A}\right)$ for the P-HEMT is increased by $120 \%$ compared with the $100 \mathrm{~V}$ C-HEMT, which mainly results from the delayed occurrence of avalanche breakdown. As shown in Figure $4 \mathrm{~b}$, it can be observed that impact ionization at the drain-side source field plate is decreased at the same $150 \mathrm{~V}$ drain bias, which results from the decreased electrons flowing from source to drain. In addition, as shown in Figure $4 \mathrm{c}$, the conduction energy $E_{C}$ level at the drain-side of the $\mathrm{p}-\mathrm{GaN}$ layer for P-HEMT is clamped, which results from the clamped $V_{C}$ as stated in section II. As shown in Figure $4 \mathrm{~d}$, for typical gate operation voltage $V_{\mathrm{GS}}=5 \mathrm{~V}$, the output curves of C-HEMT and P-HEMT are coincident well, which indicates that the PR p-GaN layer makes a negligible impact on the on-state resistance. For $V_{\mathrm{GS}}=2 \mathrm{~V}$, the $I_{\mathrm{DS}}$ for C-HEMT is slightly higher than P-HEMT, which results from the partial depletion of the 2DEG channel under the PR p-GaN layer.

Figure 5 shows the transfer characteristics of the P-HEMT. At low drain bias (such as $V_{\mathrm{DS}}=1 \mathrm{~V}$ ), the transfer curves of C-HEMT and P-HEMT are coincident well and the threshold voltage difference is less than $0.05 \mathrm{~V}$. However, with the increasing of $V_{\mathrm{DS}}$, the $V_{\mathrm{TH}}$ of C-HEMT decreases obviously while $V_{\mathrm{TH}}$ of P-HEMT slightly reduced. Typically, the $V_{\mathrm{TH}}$ decrease from $V_{\mathrm{DS}}=1 \mathrm{~V}$ to $V_{\mathrm{DS}}=50 \mathrm{~V}$ is $0.59 \mathrm{~V}$ for C-HEMT and $0.1 \mathrm{~V}$ for P-HEMT, as shown in Figure $5 \mathrm{~b}$. The significantly decreased $V_{\mathrm{TH}}$ for C-HEMT will lead to false turn-on at high drain bias (typically, from off-state to on-state), which is not acceptable for practical application. However, from the results, it can be deduced that the P-HEMT with more stable $V_{\mathrm{TH}}$ can be contributed to alleviating this problem very well. 

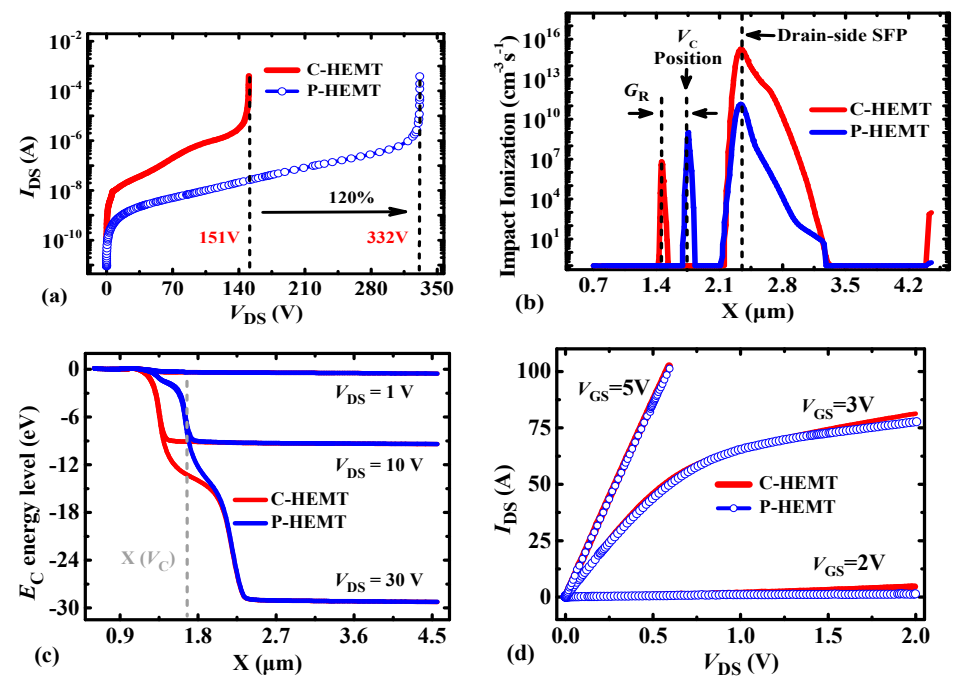

Figure 4. Comparison of the (a) forward-blocking characteristic, (b) impact ionization profile along the channel at $V_{\mathrm{DS}}=150 \mathrm{~V}$, (c) conduction energy level $E_{\mathrm{C}}$ profile along the channel, and (d) output characteristic between C-HEMT and P-HEMT.
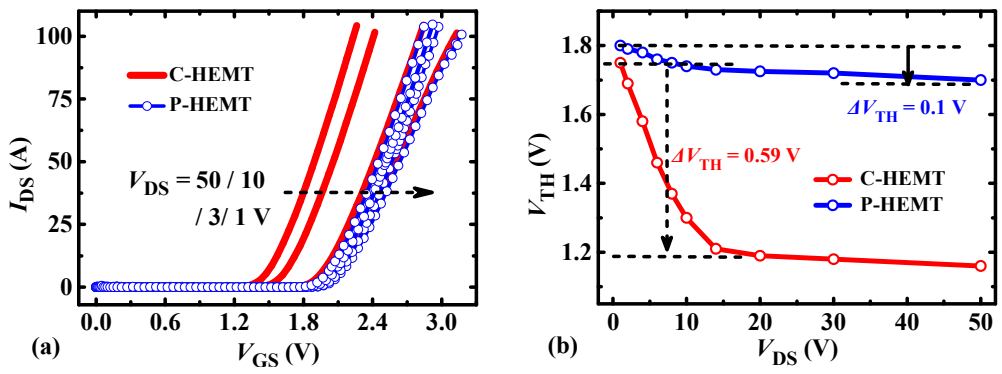

Figure 5. Comparison of (a) the transfer, $(\mathbf{b})$ the threshold voltage $V_{\mathrm{TH}}\left(\right.$ at $\left.I_{\mathrm{DS}}=10 \mathrm{~mA}\right)$ depending on $V_{\mathrm{DS}}$ between the C-HEMT and P-HEMT. For a fair comparison, the $V_{\mathrm{TH}}$ is defined when $I_{\mathrm{DS}}=10 \mathrm{~mA}$.

To illustrate the impact of the PR p-GaN layer on transient behavior, the simulation using a double pulse circuit is carried out, as shown in Figure 6. Compared with C-HEMT, the calculated turn-on loss and turn-off loss of P-HEMT are increased by $0.09 \mu \mathrm{J}$ and $0.02 \mu \mathrm{J}$ at $500 \mathrm{kHz}$ respectively, and the total switching loss is increased by less than $7.8 \%$. It can be inferred the increased switching loss mainly results from the increase of the input capacitance $C_{\text {ISS. }}$ As shown in Figure 7, it can be seen that the off-state and on-state input capacitance $C_{\text {ISS }}$ is increased by $18.9 \%$ and $47.2 \%$, respectively. In addition, as shown in Figure $7 \mathrm{a}$, the $C_{\mathrm{OSS}}$ at high-drain bias $\left(V_{\mathrm{DS}}>15 \mathrm{~V}\right)$ is the same as C-HEMT, and the output capacitance $C_{\mathrm{OSS}}$ at a low-drain bias $\left(V_{\mathrm{DS}}<15 \mathrm{~V}\right)$ is decreased by $16.7 \%$, which mainly results from the depletion of 2DEG channel under the PR layer as stated in section II. The decrease of $C_{\mathrm{OSS}}$ at $V_{\mathrm{DS}}<15 \mathrm{~V}$ is contributed to reducing the increment of switching loss.

\subsection{Design Considerations of P-HEMT}

This section mainly discusses the impact of PR p-GaN layers' thickness, length, and doping concentration on the $\mathrm{BV}$ and $V_{\mathrm{TH}}$ stability.

Figure 8 shows the $V_{\mathrm{TH}}$ and $\mathrm{BV}$ results for different thicknesses of the PR p-GaN layer. As shown in Figure 8a, it can be seen that the DIBL value is increased with PR p-GaN layer thickness. The DIBL parameter is defined as $\left(V_{T H}^{\text {High }}-V_{T H}^{\text {Low }}\right) /\left(V_{D S}^{\text {High }}-V_{D S}^{\text {Low }}\right)$ to represent the $V_{\mathrm{TH}}$ stability, and the smaller value symbolizes the more stable $V_{\mathrm{TH}}$. As shown in Figure $8 \mathrm{~b}$, it can be seen that the $V_{\mathrm{TH}}$ for different thickness PR layers from $V_{\mathrm{DS}}=1 \mathrm{~V}$ to $V_{\mathrm{DS}}=50 \mathrm{~V}$ decreases, but the difference is all less than $0.1 \mathrm{~V}$, which indicates the high stable $V_{\mathrm{TH}}$ for P-HEMT. The log-scale transfer characteristics are as shown in Figure 8c-e. For the same drain bias, the $V_{\mathrm{TH}}$ slightly increases $(\leq 0.05 \mathrm{~V})$ with the thickness of the PR 
p-GaN layer, which mainly results from the 2DEG depletion under the PR p-GaN layer. In addition, it can be observed that the BV is all larger than $320 \mathrm{~V}$, which indicates the impact of the PR p-GaN layer's thickness on BV is negligible. However, for a smaller thickness PR p-GaN layer, the gate-to-source breakdown voltage can be reduced. Figure 9a shows the $I_{\mathrm{GS}}-V_{\mathrm{GS}}$ characteristics for $20 / 30 / 40 \mathrm{~nm}$ PR p-GaN layer, and it can be seen that the $I_{\mathrm{GS}}$ for $T_{\mathrm{p} 2}=20 \mathrm{~nm}$ abruptly increases when $V_{\mathrm{GS}}$ is larger than $5.1 \mathrm{~V}$. To explore the origin of the abrupt $I_{\mathrm{GS}}$, the current distribution of the three thickness PR p-GaN layer devices are plotted, as shown in Figure $9 \mathrm{~b}-\mathrm{d}$. For the device with $T_{\mathrm{p} 2}=20 \mathrm{~nm}$, the current density from the PR p-GaN layer to the 2DEG channel is larger than the normal thickness p-GaN layer. This indicates the high gate current mainly results from the breakdown of the PR $\mathrm{p}$-GaN layer. As a comparison, the gate current density for $T_{\mathrm{p} 2}=30 / 40 \mathrm{~nm}$ is very small. Based on the above analysis, it can be deduced that the PR p-GaN layer thickness should be taken into careful consideration in the design to avoid gate breakdown.
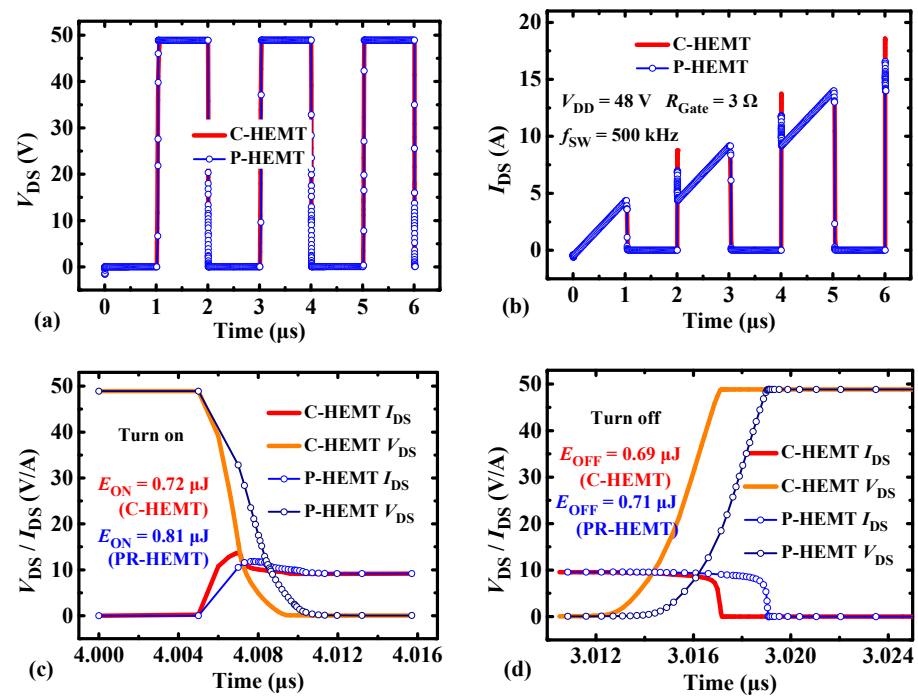

Figure 6. The switching transient comparison between C-HEMT and P-HEMT by double-pulse simulation. (a) $V_{\mathrm{DS}}$ voltage waveforms; (b) $I_{\mathrm{DS}}$ current waveforms; (c) turn on transient at $\sim 10 \mathrm{~A} I_{\mathrm{DS}}$ current; (d) turn off transient at $\sim 10$ A $I_{\mathrm{DS}}$ current.
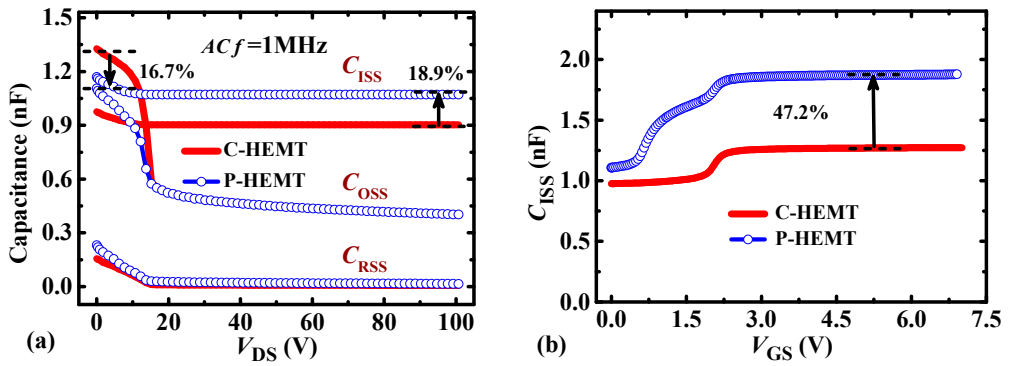

Figure 7. Comparison of (a) capacitance- $V_{\mathrm{DS}}$, and (b) $C_{\mathrm{ISS}}-V_{\mathrm{GS}}$ characteristics between C-HEMT and P-HEMT.

Figure 10 shows the impact of PR p-GaN layer length on the BV and $V_{\mathrm{TH}}$ characteristics. It can be seen that DIBL decreases with $G_{\mathrm{r}}$, which indicates the $V_{\mathrm{TH}}$ stability is increased. However, the DIBL tends to be stable and the BV decreases when $G_{\mathrm{r}}$ is larger than $0.5 \mu \mathrm{m}$. The decrease of the $\mathrm{BV}$ mainly results from the high electric field at the drain-side of the PR p-GaN layer, as shown in Figure 11. Therefore, it can be deduced that the PR p-GaN layer length should be in a reasonable range to get a good trade-off for $V_{\mathrm{TH}}$ stability and high BV. For the $100 \mathrm{~V}$ p-GaN HEMT discussed in this paper, the 0.3 0.5 $\mu \mathrm{m}$ PR p-GaN layer is recommended. 

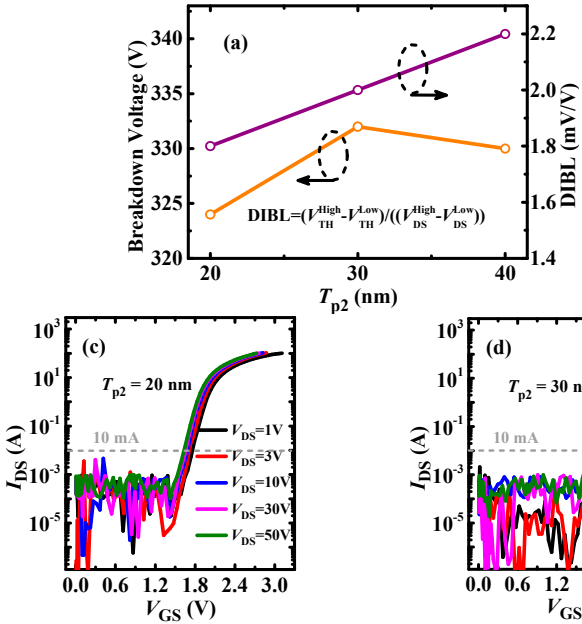
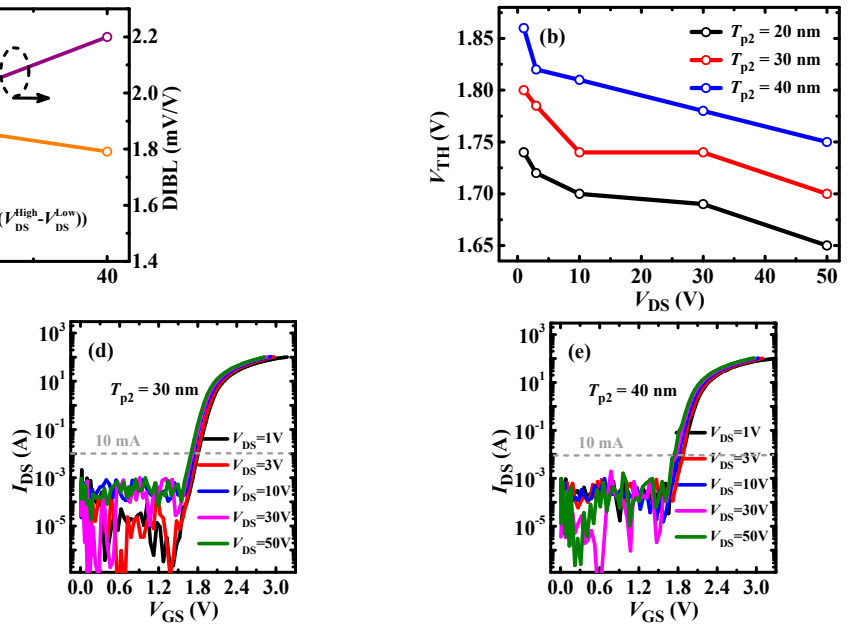

Figure 8. (a) Breakdown voltage (BV) and DIBL versus PR thickness; (b) the threshold voltage $V_{\mathrm{TH}}$ (at $I_{\mathrm{DS}}=10 \mathrm{~mA}$ ) depending on $V_{\mathrm{DS}}$; the transfer characteristics of P-HEMT with $T_{\mathrm{p} 2}=$ (c) $20 \mathrm{~nm}$; (d) $30 \mathrm{~nm}$; (e) $40 \mathrm{~nm}$.
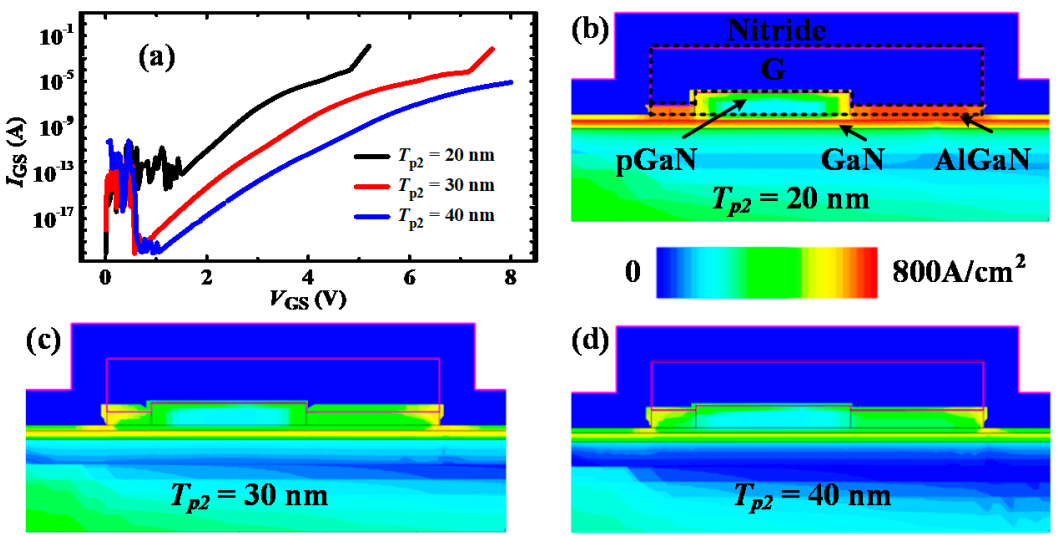

Figure 9. (a) The $I_{\mathrm{GS}}-V_{\mathrm{GS}}$ characteristics of P-HEMT with different $T_{\mathrm{p} 2}$; the current distribution at the gate part for $T_{\mathrm{p} 2}=(\mathbf{b}) 20 \mathrm{~nm},(\mathbf{c}) 30 \mathrm{~nm},(\mathbf{d}) 40 \mathrm{~nm}$.
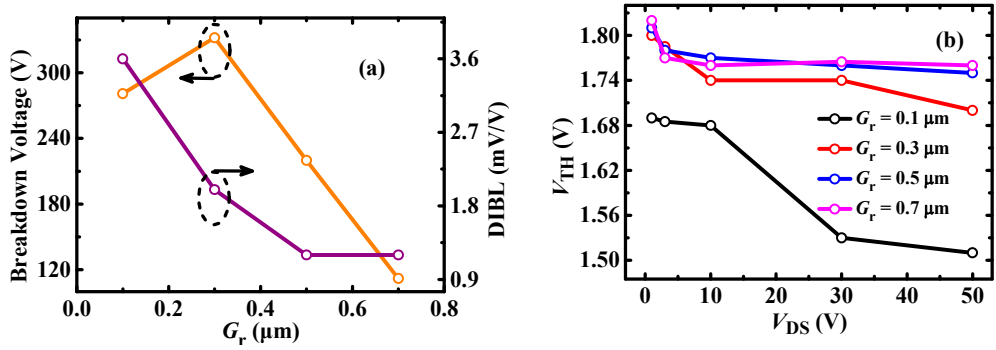

Figure 10. (a) BV and DIBL, (b) $V_{\mathrm{TH}}\left(\right.$ at $I_{\mathrm{DS}}=10 \mathrm{~mA}$ ) depending on $V_{\mathrm{DS}}$ for different $G_{\mathrm{r}}$ length.

Figure 12 shows the impact of p-GaN doping density on the $V_{\mathrm{TH}}$ and BV. It can be observed that the p-GaN doping density mainly determines the magnitude of $V_{\mathrm{TH}}$, and it makes a negligible effect on BV and DIBL. Figure 13 shows the $V_{\mathrm{TH}}$ and BV characteristics of P-HEMT with different gate lengths $L_{g}$. It can be seen that longer gate length induces higher $V_{\mathrm{TH}}$, lower DIBL, which means longer gate length is contributed to making $V_{\mathrm{TH}}$ more stable. In addition, longer gate length induces higher BV, which mainly results from the electric field modulation. However, longer gate length will induce higher on-resistance. Therefore, the gate length should be taken into careful consideration to get a better trade-off for $V_{\mathrm{TH}}$ stability, $\mathrm{BV}$, and $R_{\mathrm{ON}}$. 

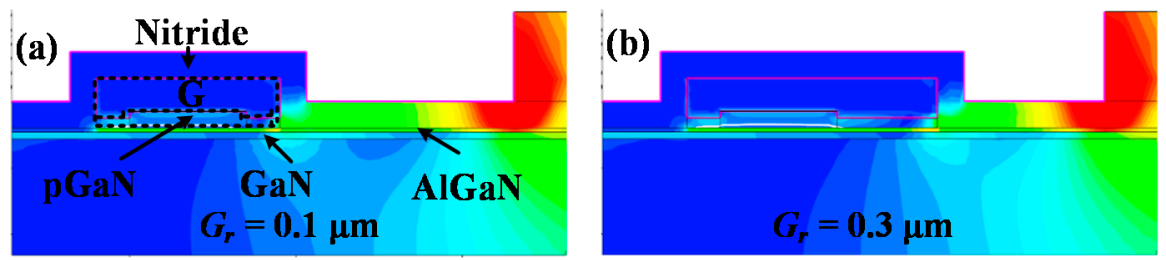

$\mathbf{0}$

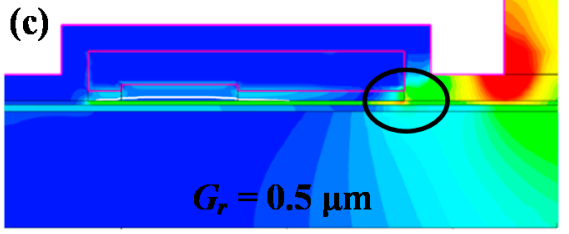

\section{$3.5 \times 10^{6} \mathrm{~V} / \mathrm{cm}$}

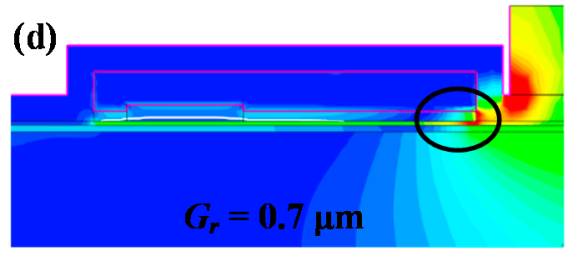

Figure 11. The electric field distribution of P-HEMT for Gr $=(\mathbf{a}) 0.1 \mu \mathrm{m}$; (b) $0.3 \mu \mathrm{m}$; (c) $0.5 \mu \mathrm{m}$; (d) $0.7 \mu \mathrm{m}$ at breakdown voltage.
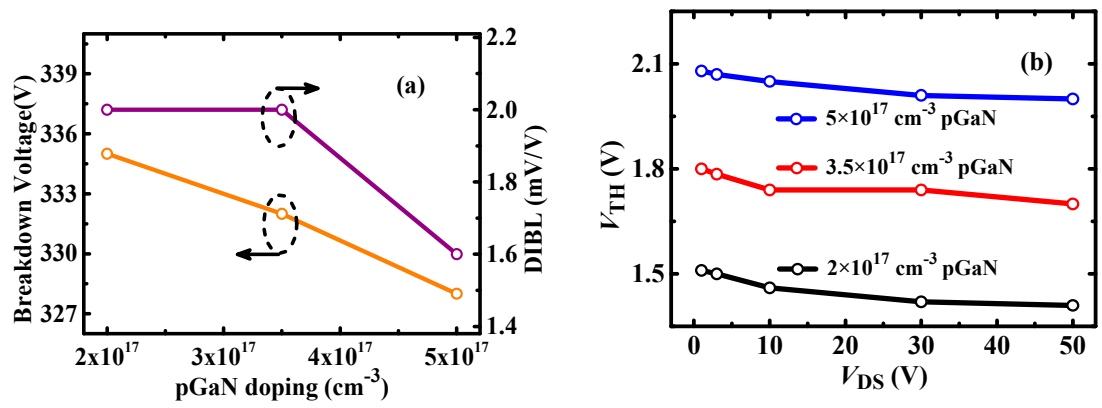

Figure 12. (a) $\mathrm{BV}$ and $\mathrm{DIBL}$, (b) $V_{\mathrm{TH}}\left(\right.$ at $\left.I_{\mathrm{DS}}=10 \mathrm{~mA}\right)$ depending on $V_{\mathrm{DS}}$ for different $\mathrm{p}-\mathrm{GaN}$ doping density.
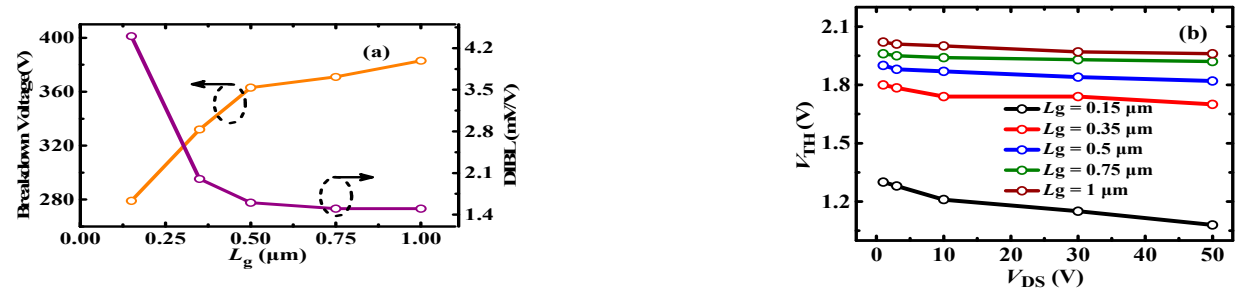

Figure 13. (a) BV and DIBL, (b) $V_{\mathrm{TH}}$ depending on $V_{\mathrm{DS}}$ for different gate lengths.

\section{Conclusions}

This paper proposes a novel p-GaN HEMT with a PR p-GaN layer to improve BV and $V_{\mathrm{TH}}$ stability. The device features a PR p-GaN layer compared with conventional $\mathrm{p}-\mathrm{GaN}$ HEMT. At high drain bias, the two-dimensional electron gas channel under the PR p-GaN layer is depleted to withstand $V_{\mathrm{DS}}$, thereby contributing to improving the BV and $V_{\mathrm{TH}}$ stability. Compared with the C-HEMT, simulation results show that the breakdown voltage is improved by $120 \%$, and the $V_{\mathrm{TH}}$ stability changing with $V_{\mathrm{DS}}$ is increased by $490 \%$ (the decrease of $V_{\mathrm{TH}}$ at $50 \mathrm{~V}$ for P-HEMT and C-HEMT are $0.1 \mathrm{~V}$ and $0.59 \mathrm{~V}$ respectively). The static transfer and output characteristics are the same as the C-HEMT, and the total switching loss at $500 \mathrm{kHz}$ is increased less than $7.8 \%$. In addition, we investigated the impact of the PR layers' length, thickness, doping density on the performance.

Author Contributions: Methodology, H.W.; investigation, H.W., Y.S., Y.X., and C.L.; writing-review and editing, Y.S., and Y.X.; supervision, G.L.; project administration, Y.H. All authors have read and agreed to the published version of the manuscript.

Funding: This work was supported by the National Key R\&D Program of China (No. 2020YFF0218503). 
Institutional Review Board Statement: Not applicable.

Informed Consent Statement: Not applicable.

Data Availability Statement: Not applicable.

Conflicts of Interest: The authors declare no conflict of interest. The funders had no role in the design of the study; in the collection, analyses, or interpretation of data; in the writing of the manuscript, or in the decision to publish the results.

\section{References}

1. Chen, W.; Wong, K.-Y.; Chen, K.J. Single-Chip Boost Converter Using Monolithically Integrated AlGaN/GaN Lateral Field-Effect Rectifier and Normally Off HEMT. IEEE Electron Device Lett. 2009, 30, 430-432. [CrossRef]

2. Meneghini, M.; Cibin, G.; Bertin, M.; Hurkx, G.A.M.; Ivo, P.; Šonský, J.; Croon, J.A.; Meneghesso, G.; Zanoni, E. OFF-state degradation of $\mathrm{AlGaN} / \mathrm{GaN}$ power HEMTs: Experimental demonstration of time-dependent drain-source breakdown. IEEE Trans. Electron Devices 2014, 61, 1987-1992. [CrossRef]

3. Meneghini, M.; Hilt, O.; Fleury, C.; Silvestri, R.; Capriotti, M.; Strasser, G.; Pogany, D.; Bahat-Treidel, E.; Brunner, F.; Knauer, A. Normally-off GaN-HEMTs with p-type gate: Off-state degradation, forward gate stress and ESD failure. Microelectron. Reliab. 2016, 58, 177-184. [CrossRef]

4. Wang, H.; Wei, J.; Xie, R.; Liu, C.; Tang, G.; Chen, K.J. Maximizing the performance of 650-V p-GaN gate HEMTs: Dynamic RON characterization and circuit design considerations. IEEE Trans. Power Electron. 2016, 32, 5539-5549. [CrossRef]

5. Ishida, H.; Kajitani, R.; Kinoshita, Y.; Umeda, H.; Ujita, S.; Ogawa, M.; Tanaka, K.; Morita, T.; Tamura, S.; Ishida, M.; et al. GaN-based Semiconductor Devices for Future Power Switching Systems. In Proceedings of the 2016 IEEE International Electron Devices Meeting (IEDM), San Francisco, CA, USA, 3-7 December 2016.

6. Chen, K.J.; Häberlen, O.; Lidow, A.; Tsai, C.L.; Ueda, T.; Uemoto, Y.; Wu, Y. GaN-on-Si power technology: Devices and applications. IEEE Trans. Electron Devices 2017, 64, 779-795. [CrossRef]

7. Kim, J.G.; Cho, C.; Kim, E.; Hwang, J.S.; Park, K.H.; Lee, J.H. High Breakdown Voltage and Low-Current Dispersion in AlGaN/GaN HEMTs with High-Quality AlN Buffer Layer. IEEE Trans. Electron Devices 2021, 68, 1513-1517. [CrossRef]

8. Duan, B.; Yang, L.; Wang, Y.; Yang, Y. Experimental Results for AlGaN/GaN HEMTs Improving Breakdown Voltage and Output Current by Electric Field Modulation. IEEE Trans. Electron Devices 2021, 68, 2240-2245. [CrossRef]

9. Xin, Y.; Chen, W.; Sun, R.; Shi, Y.; Liu, C.; Xia, Y.; Wang, F.; Li, M.L.J.; Zhou, Q.; Deng, X.; et al. Analytical Switching Loss Model for GaN-Based Control Switch and Synchronous Rectifier in Low-Voltage Buck Converters. IEEE J. Emerg. Sel. Top. Power Electron. 2019, 7, 1485-1495. [CrossRef]

10. Zhao, X.; Xu, Y.; Jia, Y.; Wu, Y.; Xu, R.; Li, J.; Hu, Z.; Wu, H.; Dai, W.; Cai, S. Temperature-Dependent Access Resistances in Large-Signal Modeling of Millimeter-Wave AlGaN/GaN HEMTs. IEEE Trans. Microw. Theory Tech. 2017, 65, 2271-2278. [CrossRef]

11. Das, S.; Kundu, S. Simulation to Study the Effect of Oxide Thickness and High-K Dielectric on Drain-Induced Barrier Lowering in N-type MOSFET. IEEE Trans. Nanotechnol. 2013, 12, 945-947. [CrossRef]

12. Park, P.S.; Rajan, S. Simulation of Short-Channel Effects in N- and Ga-Polar AlGaN/GaN HEMTs. IEEE Trans. Electron Devices 2011, 58, 704-708. [CrossRef]

13. Singisetti, U.; Wong, M.H.; Dasgupta, S.; Swenson, B.; Thibeault, B.J.; Speck, J.S.; Mishra, U.K. Enhancement-Mode N-Polar GaN MISFETs with Self-Aligned Source/Drain Regrowth. IEEE Electron Device Lett. 2011, 32, 137-139. [CrossRef]

14. Pinchbeck, J.; Lee, K.B.; Jiang, S.; Houston, P. Dual metal gate AlGaN/GaN high electron mobility transistors with improved transconductance and reduced short channel effects. J. Phys. D Appl. Phys. 2021, 54, 105104. [CrossRef]

15. Lu, B.; Saadat, O.I.; Palacios, T. High-Performance Integrated Dual-Gate AlGaN/GaN Enhancement-Mode Transistor. IEEE Electron Device Lett. 2010, 31, 990-992. [CrossRef]

16. Synopsys. TCAD Sentaurus ${ }^{\mathrm{TM}}$ Tutorial. Available online: http://www.sentaurus.dsod.pl/index.html (accessed on 19 January 2022).

17. Wang, F.; Chen, W.; Xu, X.; Sun, R.; Wang, Z.; Xia, Y.; Xin, Y.; Liu, C.; Zhou, Q.; Zhang, B. Simulation Study of an Ultralow Switching Loss p-GaN Gate HEMT With Dynamic Charge Storage Mechanism. IEEE Trans. Electron Devices 2021, 68, 175-183. [CrossRef]

18. Lidow, A.; de Rooij, M.; Strydom, J.; Reusch, D.; Glaser, J. GaN Transistors for Efficient Power Conversion; John Wiley \& Sons: Hoboken, NJ, USA, 2019.

19. Joshi, V.; Tiwari, S.P.; Shrivastava, M. Part I: Physical Insight Into Carbon-Doping-Induced Delayed Avalanche Action in GaN Buffer in AlGaN/GaN HEMTs. IEEE Trans. Electron Devices 2019, 66, 561-569. [CrossRef]

20. Verzellesi, G.; Morassi, L.; Meneghesso, G.; Meneghini, M.; Zanoni, E.; Pozzovivo, G.; Lavanga, S.; Detzel, T.; Häberlen, O.; Curatola, G. Influence of Buffer Carbon Doping on Pulse and AC Behavior of Insulated-Gate Field-Plated Power AlGaN/GaN HEMTs. IEEE Electron Device Lett. 2014, 35, 443-445. [CrossRef]

21. Chini, A.; Meneghesso, G.; Meneghini, M.; Fantini, F.; Verzellesi, G.; Patti, A.; Iucolano, F. Experimental and Numerical Analysis of Hole Emission Process From Carbon-Related Traps in GaN Buffer Layers. IEEE Trans. Electron Devices 2016, 63, 3473-3478. [CrossRef] 
22. EPC. eGaN FET Datasheet. Available online: https://epc-co.com/epc/Portals/0/epc/documents/datasheets/epc2001_ datasheet.pdf (accessed on 19 January 2022).

23. Cheng, Y.; Wang, Y.; Feng, S.; Zheng, Z.; Chen, K.J. Observation and characterization of impact ionization-induced OFF-state breakdown in Schottky-type p-GaN gate HEMTs. Appl. Phys. Lett. 2021, 118, 163502. [CrossRef]

24. Wang, F.; Chen, W.; Li, X.; Sun, R.; Zhang, B. Charge storage impact on input capacitance in p-GaN gate AlGaN/GaN power high-electron-mobility transistors. J. Phys. D Appl. Phys. 2020, 53, 305106. [CrossRef] 